\section{Zoópolis: A política e os animais no espaço público}

\section{Coltro, Fabio Zanardi}

Universidade Norte do Paraná, UNOPAR, (PR) Brasil

Oliveira, Vera Lúcia Bah de

Docente, Departamento de Biologia Geral - Universidade Estadual de Londrina -UEL- (PR) - Brasil

Durante, José Victor dos Santos

Discente, Curso de Ciências Biológicas - Universidade Estadual de Londrina -UEL- (PR) - Brasil

Diniz, Nilza Maria

Docente, Departamento de Biologia Geral - Universidade Estadual de Londrina -UEL- (PR) - Brasil, nzdiniz@gmail.com

PALAVRAS-CHAVE: Zoópolis, animaetica, agencia, animais, relação humano-animal.

O objetivo desse trabalho é trazer à tona a discussão da relação humano-animal destacada na geografia anglo-saxã a partir dos anos 1990, com uma outra interpretação do espaço com ênfase na agência dos não-humanos nas políticas públicas do Paraná com foco inicial na cidade de Londrina. Nesse cenário apresentam-se dois grandes momentos no que refere a relação dos animais e a cidade. Primeiramente há um afastamento, uma cisão, excluindo os animais das cidades em sua gênese na modernidade. Outra abordagem apresenta uma aproximação com animais e sua antropomorfização. Neste sentido a construção de uma identidade burguesa, de uma nova aristocracia vitoriana vem sendo reproduzida socialmente até os dias de hoje, abrindo espaço para os Pets na sociedade contemporânea. Nosso questionamento é no papel que os animais desempenham nesse cenário. A adoção da agência dos animais, isto é, apontar os animais como outro ator social capaz de modificar as suas relações traz a lume o questionamento do antropocentrismo dos estudos e políticas relacionadas aos não-humanos. Jennifer Wolch (1996) apresenta a tantos desafios como oportunidades para aqueles comprometidos com o eco socialismo, feminismo e antirracismo no futuro urbano em sua teoria da Zoópolis. O desafio é mudar a arraigada divisão no pensamento teórico sobre os não-humanos e seu lugar na moralidade humana. Talvez mais crucial seja a mudança política prática, onde a teoria dá lugar a situações éticas, coalizões e a formação estratégica de alianças. Suas ideias se aproximam da perspectiva de reforma da cidade para incluir os animais (como uma forma de renaturalização da cidade) em contraposição com a perspectiva de Donaldson e Kymlicka (2011). Essa busca integrar os animais na "nossa" sociedade (uma forma de desnaturalização da essência animal). Apontamentos de Nelson Aprobato Filho (2006) sobre a influência dos animais, em especial dos cães, na urbanização emergente da cidade de São Paulo, levantam a possibilidade de estudos sobre a questão animal e o planejamento urbano, através de suas políticas públicas, no âmbito local e vislumbrando a necessidade de debates sobre a inclusão e exclusão dos animais nas agendas políticas locais, deslocando o discurso antropocentrista em vigor até o momento e abrindo o debate para outros olhares, através das legislações municipais. Assim, numa análise preliminar feita com a legislação municipal dos últimos 30 anos, foi evidenciado que os termos animais e cães tiveram um aumento nos últimos 10 anos, coincidindo com o aumento também das preocupações e a discussão sobre o bem-estar animal e o papel dos animais como agentes. Foram catalogadas inicialmente 65 leis e projetos de leis que contem a palavra "animais" e com a palavra "cães" foram encontrados 14 legislações. A pesquisa aponta que a mudança no comportamento legal, ou seja, na regulação sobre animais se deu durante os anos de 1990 e coincide com as discussões sobre a agência dos animais.

\section{REFERÊNCIAS}

[1] APROBATO FILHO, Nelson. O couro e o aço: sob a mira do moderno -. 2007. Tese (Doutorado em História Social) - Faculdade de Filosofia, Letras e Ciências Humanas, Universidade de São Paulo, São Paulo, 2007.

[2] DONALDSON, Sue; KYMLICKA, Will. Zoopolis: A political theory of animal rights. Oxford University Press, 2011.

[3] WOLCH, Jennifer. Zoöpolis*. Capitalism nature socialism, v. 7, n. 2, p. 21-47, 1996. 